\title{
Chemisorption of benzene on metal dimer anions: A study by photoelectron detachment spectroscopy
}

\author{
G. Lüttgens, N. Pontius, C. Friedrich, R. Klingeler, P. S. Bechthold, M. Neeb, \\ and W. Eberhardt \\ Institut für Festkörperforschung, Forschungszentrum Jülich GmbH, 52425 Jülich, Germany
}

(Received 18 October 2000; accepted 27 February 2001)

\begin{abstract}
Photoelectron detachment spectra of $\mathrm{M}_{2}\left(\mathrm{C}_{6} \mathrm{H}_{6}\right)^{-}(\mathrm{M}=\mathrm{Pt}, \mathrm{Pd}, \mathrm{Pb})$ have been measured in the gas phase using photon energies of a Nd:YAG laser. The vibrationally resolved ground state transition from the anion to the neutral reveals an adiabatic electron affinity of $(2.01 \pm 0.05) \mathrm{eV}$ and $(0.88 \pm 0.05) \mathrm{eV}$ for $\mathrm{Pt}_{2}\left(\mathrm{C}_{6} \mathrm{H}_{6}\right)$ and $\mathrm{Pd}_{2}\left(\mathrm{C}_{6} \mathrm{H}_{6}\right)$, respectively. A ground state vibrational energy of $(24.2 \pm 1) \mathrm{meV}$ has been resolved for $\mathrm{Pt}_{2}\left(\mathrm{C}_{6} \mathrm{H}_{6}\right)$. The corresponding vibrational energy of $\mathrm{Pt}_{2}\left(\mathrm{C}_{6} \mathrm{H}_{6}\right)^{-}$amounts to $(19.0 \pm 1.0) \mathrm{meV}$. The ground state vibrational energies of $\mathrm{Pd}_{2}\left(\mathrm{C}_{6} \mathrm{H}_{6}\right)$ and $\mathrm{Pd}_{2}\left(\mathrm{C}_{6} \mathrm{H}_{6}\right)^{-}$are $(20.3 \pm 1.0) \mathrm{meV}$ and $(18.0 \pm 2.0) \mathrm{meV}$, respectively. The small vibrational frequencies suggest a perpendicular coordination $\left(C_{6 v}\right.$-symmetry) of the benzene-adsorbed transition metal dimers. $\mathrm{Pb}_{2}$, on the other hand, is bound parallel to the benzene plane ( $C_{2 v}$-symmetry). A closed shell ground state electron configuration is postulated for $\mathrm{Pb}_{2}\left(\mathrm{C}_{6} \mathrm{H}_{6}\right)$ in contrast to the triplet ground state of unreacted $\mathrm{Pb}_{2}$. The vertical electron affinity of $\mathrm{Pb}_{2}\left(\mathrm{C}_{6} \mathrm{H}_{6}\right)$ is $(1.95 \pm 0.05) \mathrm{eV}$. (ㅇ 2001 American Institute of Physics. [DOI: 10.1063/1.1366333]
\end{abstract}

\section{INTRODUCTION}

In view of the local character of chemisorption, reactions of clusters with molecules can deliver useful information with respect to catalytic processes on macroscopic metal surfaces. ${ }^{1,2}$ So far, organometallic complexes with single metal atoms have been studied in great detail because many of them can be produced by chemical synthesis, e.g., ferrocene. ${ }^{3-6}$ Studies of mononuclear metal complexes deliver information primarily on the ligand-metal interaction. Chemisorption on metal dimers and clusters, on the other hand, is of interest as they provide additional information about larger "metallic" centers and about the influence on the metal-metal bond.

In spite of the potential technological importance in surface chemistry and heterogeneous catalysis, information on the electronic structure of organometallic clusters is quite rare, especially for those that cannot be produced by standard chemical synthesis. Photodetachment electron spectroscopy is a powerful method in order to explore the electronic structure of mass-separated cluster anions in the gas phase. ${ }^{7-10}$ Anionic clusters can be produced from plasma sources using laser vaporization or arc discharge. Electrically charged clusters are suitable for mass-separation by time-of-flight which provides both a high cluster transmission and a wide mass range. In the case of metal clusters, photodetachment provides information on the metal-like orbitals which are generally located close to the detachment threshold. Aromatic molecules (arenes) are particularly suitable for adsorption on metals due to a high $\pi$-electron density perpendicular to the aromatic molecular plane. The frontier orbitals of arenes are highly suitable to hybridize with the $d$-orbitals of transition metals due to the formation of donation and back-donation bonds. The orbital energies of the arenes are usually located at higher binding energies than the metallic orbitals due to the stability of the aromatic molecules and the large gap between the occupied and unoccupied frontier orbitals of the arenes. Consequently, the comparison of the photoelectron spectra of the unreacted bare metal clusters with those of the corresponding chemically reacted clusters is helpful to probe changes of the valence orbital structure of the cluster core as a function of the adsorbate molecule.

The chemical reactivity of benzene with transition metal clusters has extensively been studied by mass spectroscopy. ${ }^{11-14}$ Photofragmentation, ionization energies, physisorption, and chemisorption as well as charge transfer processes have explicitly been discussed. Ab initio calculations have recently been carried out for small transition metal-benzene clusters like $\mathrm{Rh}_{2}\left(\mathrm{C}_{6} \mathrm{H}_{6}\right)^{+}, \operatorname{Pt}\left(\mathrm{C}_{6} \mathrm{H}_{6}\right)^{+}$, and $\mathrm{Pt}\left(\mathrm{C}_{6} \mathrm{H}_{6}\right) .{ }^{15,16}$ Also, polynuclear vanadium benzene sandwich clusters have been studied both theoretically and experimentally. ${ }^{17,18}$ A photoelectron study of $\mathrm{V}\left(\mathrm{C}_{6} \mathrm{H}_{6}\right)^{-}$has recently been published by Judai et al. ${ }^{19}$

Here we have explored benzene-reacted metal dimers which provide information about the differences of chemisorption on a transition metal vs a main group metal. The bonding of benzene onto Pt and Pd is expected to be principally different from that onto $\mathrm{Pb}$ due to the participation of $d$-orbitals. Photoelectron spectroscopy is a general probe to expose these differences. Moreover, by resolving the intermetallic vibration we will gain information on the intermetallic bond strength and bond distance changes of the chemically reacted metal dimers.

\section{EXPERIMENT}

The photoelectron spectra of the mono-benzene metal dimer anions, $\mathrm{M}_{2}\left(\mathrm{C}_{6} \mathrm{H}_{6}\right)^{-}(\mathrm{M}=\mathrm{Pt}, \mathrm{Pd}, \mathrm{Pb})$ have been recorded after mass selecting the clusters in a molecular beam setup. The metal clusters have been produced by condensa- 


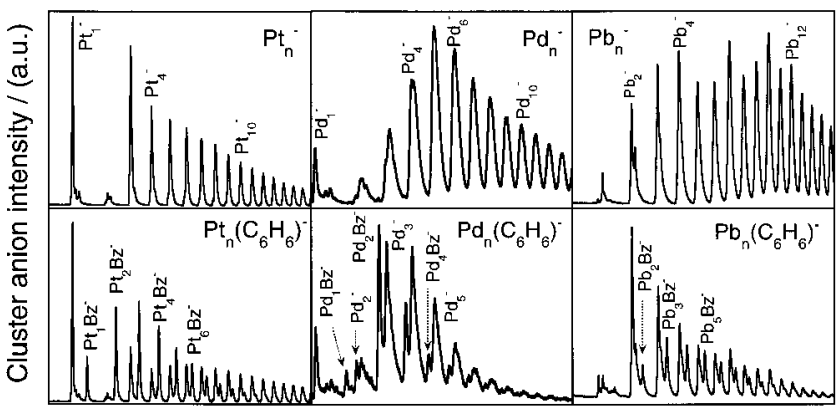

Time of flight / (a.u.)

FIG. 1. Time-of-flight mass spectra of bare and benzene-adsorbed metal cluster anions. The spectra in the upper row show the cluster distribution of bare $\mathrm{Pt}_{n}^{-}, \mathrm{Pd}_{n}^{-}$, and $\mathrm{Pb}_{n}^{-}$clusters as produced by a laser evaporation cluster source. The bottom row shows mass spectra of mono(benzene)-metal cluster anions $\mathrm{M}_{n}\left(\mathrm{C}_{6} \mathrm{H}_{6}\right)^{-}$with $\mathrm{M}=\mathrm{Pt}, \mathrm{Pd}, \mathrm{Pb}$. The chemically reacted mono(benzene)-metal clusters have been synthesized subsequently to metal cluster condensation.

tion of laser-vaporized metal plasma in a He-carrier gas at a repetition rate of $20 \mathrm{~Hz}$. Gas phase benzene (vapor pressure $\sim 50$ mbar) has been injected by a separate adsorbate valve mounted immediately behind the condensation zone. The pure and reacted clusters are cooled in a subsequent adiabatic expansion (20 bar initial pressure, $200 \mu$ s He-valve opening time). Negatively charged clusters were then accelerated to a kinetic energy of $600 \mathrm{eV}$ and focused into the electron spectrometer by a pulsed two-stage Wiley-McLaren ion optics. On the way to the photoelectron spectrometer a drift tube of $\sim 1.2 \mathrm{~m}$ was used to mass separate the clusters by their respective times of flight. Finally, the cluster anions were stopped in the source region of the electron spectrometer by a pulsed electric field. ${ }^{20}$ Electrons were photodetached from the mass-selected clusters with the fundamental wavelength and higher harmonics of a Q-switched Nd:YAG laser (1064 $\mathrm{nm}, 532 \mathrm{~nm}, 355 \mathrm{~nm}$ ). Since the experimental setup provides mass separation prior to photodetachment it guarantees an unambiguous identification of the photodetachment spectra with a given cluster mass.

The time-of-flight mass spectra of bare and reacted metal clusters are shown in Fig. 1. The upper row of panels shows the mass spectra of the nonreacted, bare $\mathrm{Pt}_{n}^{-}, \mathrm{Pd}_{n}^{-}$, and $\mathrm{Pb}_{n}^{-}$ clusters, respectively. The increased width of the Pd-mass peaks in comparison with those of $\mathrm{Pt}$ and $\mathrm{Pb}$ is due to the larger isotope distribution of $\mathrm{Pd}$. The anion mass spectra of the benzene-reacted metal clusters are shown in the bottom panel of Fig. 1. Adsorption on the very small Pt-clusters seems to be favored over adsorption on clusters with more than six Pt-atoms, as these adsorbate peaks up to the hexamer are stronger than the corresponding unreacted Ptcluster peaks. In particular, the anionic dimers of Pt and $\mathrm{Pd}$ are stabilized by benzene while the pure dimer peaks show hardly any intensity. Note that the neutral $\mathrm{Pt}_{2}$-dimer seems to be more stable, as the corresponding peak is clearly visible in the cation mass spectrum. ${ }^{11}$ This can result from fragmentation of larger clusters because in this case the neutral particles are ionized prior to detection. In our experiment the cluster anions are produced in the plasma and not by subse-

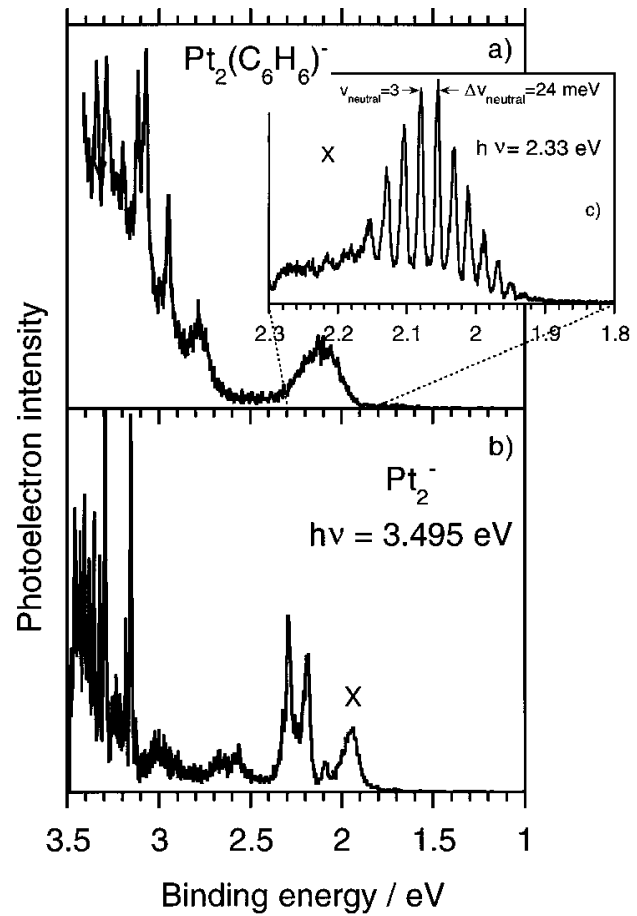

FIG. 2. Photoelectron detachment spectra of $\mathrm{Pt}_{2}\left(\mathrm{C}_{6} \mathrm{H}_{6}\right)^{-}$recorded at photon energies of $3.495 \mathrm{eV}$ (a) and $2.33 \mathrm{eV}$ (c). For comparison, the photodetachment spectrum of unreacted $\mathrm{Pt}_{2}^{-}$at $3.495 \mathrm{eV}$ is shown in (b). X labels the transition from the ground state of the anion to that of the neutral. A vibrational energy of $24.2 \mathrm{meV}$ is observed for the neutral ground state of $\mathrm{Pt}_{2}\left(\mathrm{C}_{6} \mathrm{H}_{6}\right)$.

quent electron attachment. Therefore the increased intensity of $\mathrm{Pd}_{2}\left(\mathrm{C}_{6} \mathrm{H}_{6}\right)^{-}$and $\mathrm{Pt}_{2}\left(\mathrm{C}_{6} \mathrm{H}_{6}\right)^{-}$over the unreacted metal dimer anions is presumably not due to fragmentation of larger clusters but rather due to the decreased reactivity of the ligated metal dimers to form larger clusters. In contrast to the corresponding adsorbate peaks of the transition metal clusters, the adsorbate peaks of the $\mathrm{Pb}$-dimer, $\mathrm{Pb}_{2}\left(\mathrm{C}_{6} \mathrm{H}_{6}\right)^{-}$, and $\mathrm{Pb}$-trimer, $\mathrm{Pb}_{3}\left(\mathrm{C}_{6} \mathrm{H}_{6}\right)^{-}$, are weak with respect to unreacted $\mathrm{Pb}_{2}^{-}$and $\mathrm{Pb}_{3}^{-}$. The benzene-adsorbates of the higher $\mathrm{Pb}$-clusters are almost as intense as the bare $\mathrm{Pb}_{n}(n \geqslant 4)$ clusters.

\section{A. $\mathrm{Pt}_{2}\left(\mathrm{C}_{6} \mathrm{H}_{6}\right)^{-}$}

The photodetachment spectra of $\mathrm{Pt}_{2}\left(\mathrm{C}_{6} \mathrm{H}_{6}\right)^{-}$are shown in Figs. 2(a) and 2(c), respectively. The spectrum of $\mathrm{Pt}_{2}\left(\mathrm{C}_{6} \mathrm{H}_{6}\right)^{-}$shows a leading feature at a binding energy of $2.1 \mathrm{eV}$ similar to the spectrum of $\mathrm{Pt}_{2}^{-}$shown in Fig. 2(b). This peak is attributed to the ground state transition between the anion and the neutral cluster. The energy gap of about 0.7 $\mathrm{eV}$ between the first and second peak indicates a closed shell electron configuration in neutral $\mathrm{Pt}_{2}\left(\mathrm{C}_{6} \mathrm{H}_{6}\right)$. A vibrational fine structure on the ground state electron peak has been resolved using a photon energy of $2.33 \mathrm{eV}$ [Fig. 2(c)]. About ten vibrational peaks are clearly visible. A single vibrational progression is revealed by a harmonic Franck-Condon analysis, suggesting that a single electronic state is reached in the final state. The Franck-Condon least square fit along the experimental data is shown in Fig. 3. The derived spectroscopic parameters of $\mathrm{Pt}_{2}\left(\mathrm{C}_{6} \mathrm{H}_{6}\right)$ and $\mathrm{Pt}_{2}\left(\mathrm{C}_{6} \mathrm{H}_{6}\right)^{-}$are summarized in Table I.

A vibrational energy of $24.2 \mathrm{meV}$ has been deduced for 


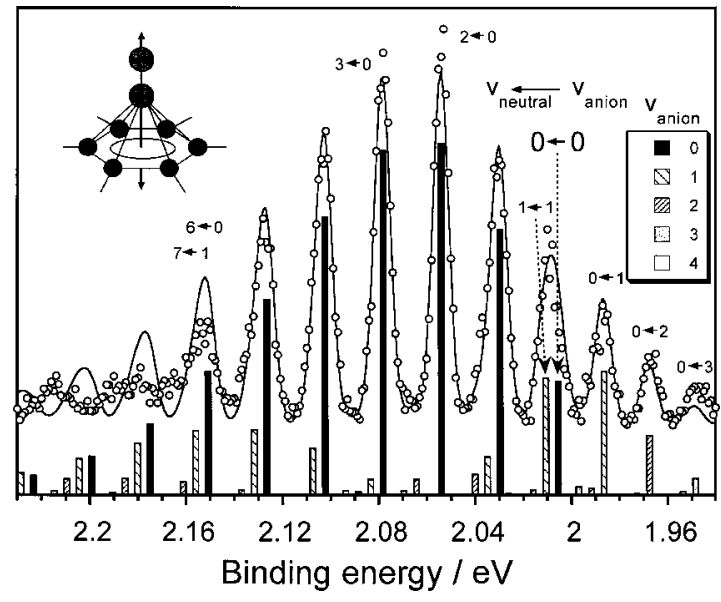

FIG. 3. Franck-Condon analysis of the vibrational fine structure on the ground state photoelectron peak of $\mathrm{Pt}_{2}\left(\mathrm{C}_{6} \mathrm{H}_{6}\right)^{-}$along the $\mathrm{Pt}-\mathrm{Pt}\left(\mathrm{C}_{6} \mathrm{H}_{6}\right)^{-}$ stretch coordinate. The adiabatic electron affinity of $\mathrm{Pt}_{2}\left(\mathrm{C}_{6} \mathrm{H}_{6}\right)$ amounts to $2.006 \mathrm{eV}$. The $0 \leftarrow 0$ transition is marked by an arrow. The vibrational peaks at lower energies are due to hot bands from vibrationally excited anions. The bar diagram represents the Franck-Condon factors corresponding to the vibrational transitions from the anionic to the neutral electronic ground state. The Franck-Condon factors were convoluted by a Gaussian to simulate the experimental broadening (full line). A smooth background has been subtracted from the experimental data. The change of the internuclear distance $\left(\Delta r_{e}\right)$ along the $\mathrm{Pt}-\mathrm{Pt}$ stretching normal coordinate of $\mathrm{Pt}_{2}\left(\mathrm{C}_{6} \mathrm{H}_{6}\right)$ as well as the vibrational energies of the anion and neutral have been used as fit parameters. Further fit parameters have been the temperature and the energy of the $0-0$ vibrational ground state transition.

the neutral final state. The two most intense vibrational peaks are due to the transitions from the anionic ground vibrational level to the vibrational final states in the neutral $v_{\text {neutral }}=2$ and 3, respectively. Moreover, a strong contribution of hotbands is revealed from the Franck-Condon analysis. The calculated $1 \leftarrow 1$ transition at $2.011 \mathrm{eV}$ is even more intense than the adiabatic vibrational transition $(0 \leftarrow 0)$ at $2.006 \mathrm{eV}$. Moreover, transitions from the second and third anionic vibrational levels are observed predominantly contributing to the transitions $0 \leftarrow 2$ and $0 \leftarrow 3$ on the low energy side. The lowest energetic peak at $\sim 1.93 \mathrm{eV}$ corresponds to the $0 \leftarrow 3$ hot-band transition (Fig. 3). The vibrational energy of the anion amounts to $19.0 \mathrm{meV}$ as taken from the fit to the hotbands. From the population of the hot bands a vibrational temperature of $(200 \pm 20) \mathrm{K}$ is revealed for the cluster anions.

The low vibrational energies for both the anionic and neutral clusters indicate an intermetallic $\mathrm{Pt}-\mathrm{Pt}$ vibrational

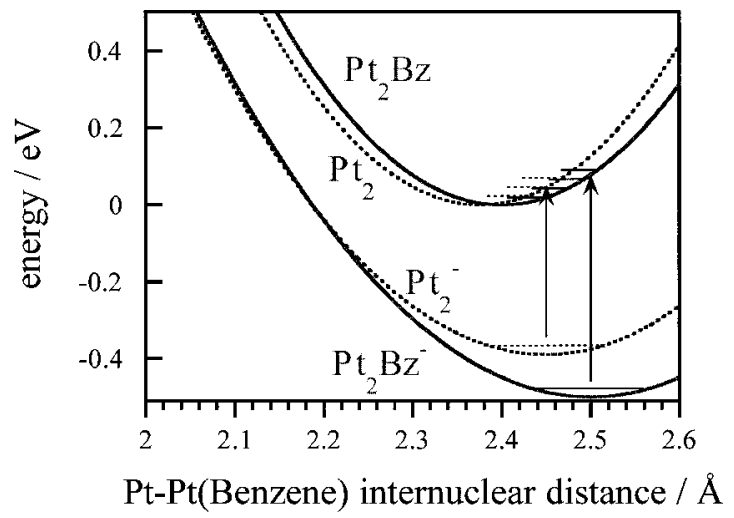

FIG. 4. The ground state potential curves of $\mathrm{Pt}_{2}\left(\mathrm{C}_{6} \mathrm{H}_{6}\right)^{-}$and $\mathrm{Pt}_{2}\left(\mathrm{C}_{6} \mathrm{H}_{6}\right)$ along the $\mathrm{Pt}-\mathrm{Pt}\left(\mathrm{C}_{6} \mathrm{H}_{6}\right)$ internuclear distance $(\mathrm{Bz}=$ Benzene) in comparison with the potential curves of the unreacted metal dimers. The spectroscopic parameters of $\mathrm{Pt}_{2}\left(\mathrm{C}_{6} \mathrm{H}_{6}\right)$ have been deduced from a harmonic FranckCondon fit to the data of the vibrationally resolved ground state transition from the anion to the neutral. The potential curves of $\mathrm{Pt}_{2}$ and $\mathrm{Pt}_{2}^{-}$have been constructed from the parameters given in Ref. 21.

mode. $\mathrm{Pt}_{2}$ and $\mathrm{Pt}_{2}^{-}$have vibrational energies of $26.7 \mathrm{meV}$ (Refs. 21 and 22) and $22.1 \mathrm{meV},{ }^{21}$ respectively. The $\mathrm{Pt}-\mathrm{Pt}$ stretching vibration of $\mathrm{Pt}_{2}(\mathrm{CO})$ has been calculated to be 24 $\mathrm{meV} .{ }^{23}$ The $\mathrm{Pt}-\mathrm{C}$ vibrational energy, on the other hand, is expected to be considerably larger as the vibrational energy of benzene on $\operatorname{Pt}(111)$ amounts to $44 \mathrm{meV} .{ }^{24}$ Therefore we attribute the observed vibrational energy of $24.2 \mathrm{meV}$ to the $\mathrm{Pt}-\mathrm{Pt}$ stretching vibration of neutral $\mathrm{Pt}_{2}\left(\mathrm{C}_{6} \mathrm{H}_{6}\right)$. The slightly lower vibrational energy with respect to free $\mathrm{Pt}_{2}$ results from the difference in the reduced masses of $\mathrm{Pt}_{2}$ and $\mathrm{Pt}_{2}\left(\mathrm{C}_{6} \mathrm{H}_{6}\right)$. Considering the reduced masses only $\left(\mu_{\mathrm{Pt}-\mathrm{PtBz}}=113.81 \mathrm{amu}\right.$, $\mu_{\mathrm{Pt}-\mathrm{Pt}}=97.54 \mathrm{amu}$ ), a Pt-Pt vibrational energy of $24.7 \mathrm{meV}$ is calculated for $\mathrm{Pt}_{2}\left(\mathrm{C}_{6} \mathrm{H}_{6}\right)$ which is only slightly larger than our experimental value. The calculated force constant indicates a typical covalent bond strength of the intermetallic bond in $\mathrm{Pt}_{2}\left(\mathrm{C}_{6} \mathrm{H}_{6}\right) .{ }^{25,26}$

The ground state spectroscopic constants of $\mathrm{Pt}_{2}\left(\mathrm{C}_{6} \mathrm{H}_{6}\right)^{-}$ and $\mathrm{Pt}_{2}\left(\mathrm{C}_{6} \mathrm{H}_{6}\right)$ are very similar to those of $\mathrm{Pt}_{2}^{-}$and $\mathrm{Pt}_{2}$, respectively (Table I). The harmonic potential curves as deduced from the spectroscopic parameters are shown in Fig. 4. Due to the larger vibrational frequency of $\mathrm{Pt}_{2}\left(\mathrm{C}_{6} \mathrm{H}_{6}\right)$ with respect to $\mathrm{Pt}_{2}\left(\mathrm{C}_{6} \mathrm{H}_{6}\right)^{-}$we believe the intermetallic bond length to be shorter in neutral $\mathrm{Pt}_{2}\left(\mathrm{C}_{6} \mathrm{H}_{6}\right)$ than in the anion, similar to $\mathrm{Pt}_{2}$ in comparison to $\mathrm{Pt}_{2}^{-}$. The intermetallic bond length difference between $\mathrm{Pt}_{2}\left(\mathrm{C}_{6} \mathrm{H}_{6}\right)$ and $\mathrm{Pt}_{2}\left(\mathrm{C}_{6} \mathrm{H}_{6}\right)^{-}$is $32 \%$

TABLE I. Spectroscopic data of $\mathrm{Pt}_{2}\left(\mathrm{C}_{6} \mathrm{H}_{6}\right)$ and $\mathrm{Pt}_{2}\left(\mathrm{C}_{6} \mathrm{H}_{6}\right)^{-}$along the intermetallic stretch coordinate $\mathrm{Pt}-\mathrm{Pt}\left(\mathrm{C}_{6} \mathrm{H}_{6}\right)$. The data have been deduced from a harmonic Franck-Condon least square fit on the vibrationally resolved ground state photoelectron peak of $\mathrm{Pt}_{2}\left(\mathrm{C}_{6} \mathrm{H}_{6}\right)^{-}$(Fig. 3). A vibrational temperature $T_{\text {vib }}=(200 \pm 20) \mathrm{K}$ of the anion has been deduced from the relative population of the hot bands.

\begin{tabular}{lllll}
\hline \hline & $\mathrm{Pt}-\mathrm{Pt}\left(\mathrm{C}_{6} \mathrm{H}_{6}\right)$ & $\mathrm{Pt}-\mathrm{Pt}\left(\mathrm{C}_{6} \mathrm{H}_{6}\right)^{-}$ & \multicolumn{1}{c}{$\mathrm{Pt}_{2}$ (Ref. 21) } & $\mathrm{Pt}_{2}^{-}$(Ref. 21) \\
\hline Electronic state & $\mathrm{X}$ & $\mathrm{X}$ & $\mathrm{X} 5 d^{18} 6 s \sigma_{g}^{2}$ & $\mathrm{X} 5 d^{18} 6 s\left(\sigma_{g}^{2} \sigma_{u}^{1}\right)$ \\
$\hbar \omega_{e} / \mathrm{meV}$ & $24.2 \pm 1.0$ & $19.0 \pm 1.0$ & $26.7 \pm 1.9$ & $22.1 \pm 2.5$ \\
$k / \mathrm{N} \mathrm{m}^{-1}$ & $255 \pm 21$ & $157 \pm 17$ & 266 & 182 \\
$\Delta r_{e} / \AA$ & $0.098 \pm 0.002$ & & $0.074 \pm 0.008$ & \\
& & & $\left(r_{e}\right.$ of anion larger $)$ & \\
Electron affinity/eV & $2.006 \pm 0.05$ & & $1.898 \pm 0.008$ & \\
\hline \hline
\end{tabular}


larger than the corresponding bond length shift upon electron detachment of $\mathrm{Pt}_{2}^{-}\left(\Delta r_{e}=7.4 \mathrm{pm}\right){ }^{21}$ According to this difference, the vertical transition shifts from $1 \leftarrow 0$ in the detachment spectrum of $\mathrm{Pt}_{2}^{-}$(Ref. 21) to somewhere between $2 \leftarrow 0$ and $3 \leftarrow 0$ in the spectrum of $\mathrm{Pt}_{2}\left(\mathrm{C}_{6} \mathrm{H}_{6}\right)^{-}$. This corresponds to an enhanced vibrational progression on the first peak of $\mathrm{Pt}_{2}\left(\mathrm{C}_{6} \mathrm{H}_{6}\right)^{-}$with respect to $\mathrm{Pt}_{2}^{-}$. Furthermore, the increased vibrational frequency with respect to the anion, indicates that the ground state photoelectron peak of $\mathrm{Pt}_{2}\left(\mathrm{C}_{6} \mathrm{H}_{6}\right)^{-}$originates from an antibonding orbital. In analogy to the ground state electron peak of $\mathrm{Pt}_{2}^{-}\left[\mathrm{X} 5 d^{18} 6 s \sigma_{g}^{2} \leftarrow \mathrm{X} 5 d^{18} 6 s\left(\sigma_{g}^{2} \sigma_{u}^{1}\right)\right]$ we tentatively attribute the first peak in the spectrum of $\mathrm{Pt}_{2}\left(\mathrm{C}_{6} \mathrm{H}_{6}\right)^{-}$to detachment from the metal-derived $6 s \sigma_{u}^{1}$ orbital.

Taking the reduced masses into account the vibrational energies of $\mathrm{Pt}_{2}\left(\mathrm{C}_{6} \mathrm{H}_{6}\right)$ and $\mathrm{Pt}_{2}\left(\mathrm{C}_{6} \mathrm{H}_{6}\right)^{-}$are $2 \%$ and $7 \%$ smaller than those of $\mathrm{Pt}_{2}$ and $\mathrm{Pt}_{2}^{-}$, respectively. Thus the intermetallic force constants of $\mathrm{Pt}_{2}\left(\mathrm{C}_{6} \mathrm{H}_{6}\right)$ and $\mathrm{Pt}_{2}\left(\mathrm{C}_{6} \mathrm{H}_{6}\right)^{-}$ are smaller than the ones of unreacted $\mathrm{Pt}_{2}$ and $\mathrm{Pt}_{2}^{-}$which suggests a net charge transfer from benzene into an antibonding $\mathrm{Pt}_{2}$-orbital.

The double feature at $2.3 \mathrm{eV}$ in the spectrum of $\mathrm{Pt}_{2}^{-}$ completely disappears in the spectrum of $\mathrm{Pt}_{2}\left(\mathrm{C}_{6} \mathrm{H}_{6}\right)^{-}$. The double feature is tentatively assigned to be due to excited final states within the $5 d \pi$-orbitals of platinum. ${ }^{22}$ With respect to symmetry adapted orbitals in $C_{6 v}\left(\mathrm{Pt}_{2}^{-}\right.$in the central position above the plane of the benzene ring; see inset in Fig. 3 ), the twofold degenerate $e_{1 g}$ orbital [highest occupied molecular orbital (HOMO)] of benzene is able to hybridize with the $d \pi_{u, g}$ orbitals of $\mathrm{Pt}_{2}$ forming a $d \pi-p \pi$ bond. A strong interaction of the corresponding Pt-orbitals with the lowlying benzene orbitals will cause a strong shift of the Pt- $5 d \pi$ orbitals to lower energy. Thus the double feature arising from excitation within the metallic $d \pi$ orbitals is supposed to be shifted to higher binding energies. Indeed, the region above $2.5 \mathrm{eV}$ reveals a wealth of sharp peaks which are considerably enhanced in the spectrum of $\mathrm{Pt}_{2}\left(\mathrm{C}_{6} \mathrm{H}_{6}\right)^{-}$with respect to $\mathrm{Pt}_{2}^{-}$[Fig. 2(b)]. A possible $d \delta_{u, g}-p \pi^{*}$ back donation from the metal $5 d \delta_{u, g}$-orbitals into the degenerate lowest unoccupied molecular orbital (LUMO) of benzene $\left(e_{2 u}\right)$ will additionally enhance the intensity within the $5 d$ region above $2.5 \mathrm{eV}$. From both the strong interaction of the $d$-orbitals and the observed metal-metal stretch vibration we conclude that the platinum dimer is most probably bound perpendicular to the benzene ring $\left(C_{6 v}\right.$-symmetry). An orientation of the dimer parallel to the plane of benzene $\left(C_{2 v}\right)$ is less probable as this would not result in a vibrational frequency close to that of free $\mathrm{Pt}_{2}$. Moreover, the observation of a metal-like vibrational frequency of $\mathrm{Pt}_{2}\left(\mathrm{C}_{6} \mathrm{H}_{6}\right)^{-}$indicates that the platinum dimer does not dissociate upon benzenechemisorption in contrast to the reaction of $\mathrm{V}_{n}^{-}$clusters with benzene. ${ }^{17,18}$

As suggested by the $C_{6 v}$-symmetry, the benzene molecule is coordinated merely to one of the two metal-dimer atoms. This so-called "atop" position $\left(C_{6 v}\right)$ is not favored on densely packed metal surfaces. Instead, the benzene molecule prefers two- and threefold coordinated bridge and hollow sites causing local $C_{2 v^{-}}$and $C_{3 v^{-}}$-symmetries ${ }^{2,27-32}$ on densely packed metal surfaces.
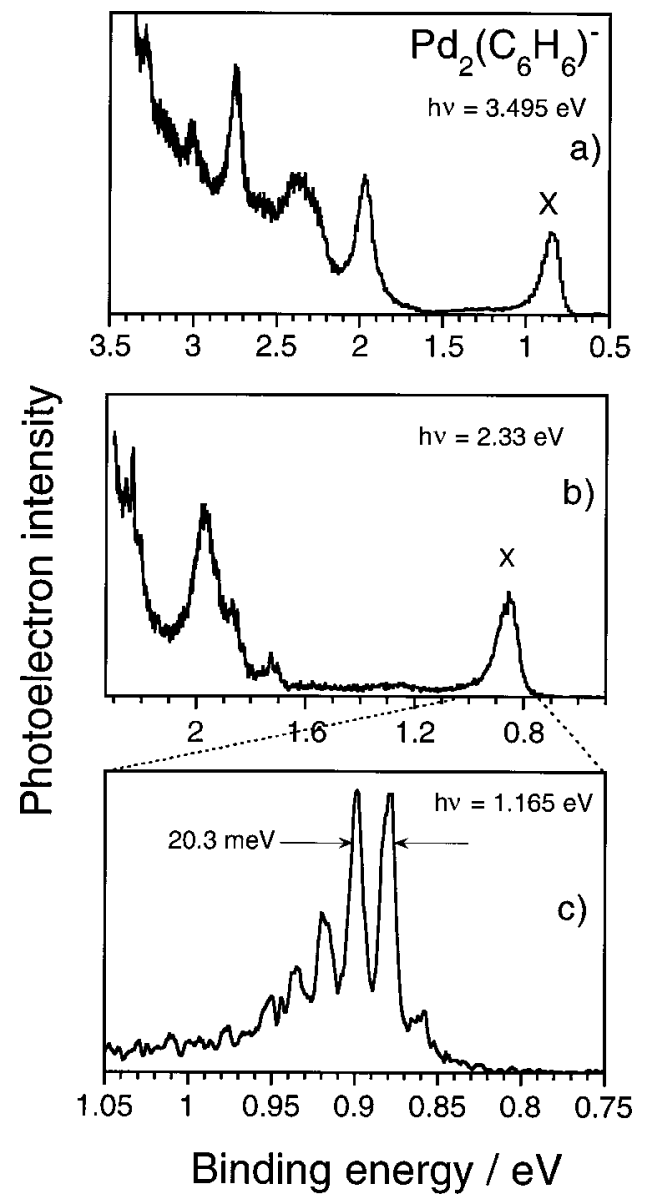

FIG. 5. Photoelectron detachment spectra of $\mathrm{Pd}_{2}\left(\mathrm{C}_{6} \mathrm{H}_{6}\right)^{-}$recorded at photon energies of $3.495 \mathrm{eV}$ (a), $2.330 \mathrm{eV}$ (b), and $1.165 \mathrm{eV}$ (c). X labels the electronic transition from the ground state of the anion to that of the neutral. A vibrational energy of $20.3 \mathrm{meV}$ is observed for the ground state photoelectron peak of the neutral.

The intermetallic $\sigma$-bond $\left(s, d_{z}\right)$ is most probably not involved in the bonding to benzene neither on the surface nor on the dimer. This is different to the adsorption of nonaromatic molecules like $\mathrm{CO}$ and $\mathrm{N}_{2}$ where the bonding preferentially takes place via a $\sigma$-donor bonding from the adsorbate into the antibonding $(s, d) \sigma^{*}$ - orbitals of the metal. ${ }^{9,23,33,34}$ The back-donation, on the other hand, occurs via the hybridization between the $\mathrm{CO} \pi^{*}$ and the Pt $5 d$ orbitals in analogy to the back donation in the arene-metal compounds.

\section{B. $\mathrm{Pd}_{2}\left(\mathrm{C}_{6} \mathrm{H}_{6}\right)^{-}$}

Photodetachment spectra of $\mathrm{Pd}_{2}\left(\mathrm{C}_{6} \mathrm{H}_{6}\right)^{-}$measured at photon energies of $3.495 \mathrm{eV}, 2.33 \mathrm{eV}$, and $1.165 \mathrm{eV}$, respectively, are shown in Fig. 5. A narrow peak is seen at $0.9 \mathrm{eV}$. This leading peak is separated from the remaining peaks by nearly $1 \mathrm{eV}$. Using the fundamental wavelength of the $\mathrm{Nd}$ :YAG laser a vibrational fine structure has been resolved on the ground state peak [Fig. 5(c)]. A hot band is visible on the low-energy side. An anharmonic Franck-Condon least square fit reveals an adiabatic transition energy at $0.876 \mathrm{eV}$ and an anharmonicity constant of $0.5 \mathrm{meV}$ for the neutral. The spectroscopic data are summarized in Table II. Figure 6 
TABLE II. Spectroscopic data of $\mathrm{Pd}_{2}\left(\mathrm{C}_{6} \mathrm{H}_{6}\right)$ and $\mathrm{Pd}_{2}\left(\mathrm{C}_{6} \mathrm{H}_{6}\right)^{-}$along the intermetallic stretch coordinate $\mathrm{Pd}-\mathrm{Pd}\left(\mathrm{C}_{6} \mathrm{H}_{6}\right)$. The data have been taken from an anharmonic Franck-Condon least square fit on the vibrationally-resolved ground state photoelectron peak of $\mathrm{Pd}_{2}\left(\mathrm{C}_{6} \mathrm{H}_{6}\right)^{-}$(Fig. 6). A vibrational temperature $T_{\mathrm{vib}}=(140 \pm 50) \mathrm{K}$ of the anion has been deduced from the relative population of the hot band.

\begin{tabular}{lllll}
\hline \hline & $\mathrm{Pd}-\mathrm{Pd}\left(\mathrm{C}_{6} \mathrm{H}_{6}\right)$ & $\mathrm{Pd}-\mathrm{Pd}\left(\mathrm{C}_{6} \mathrm{H}_{6}\right)^{-}$ & $\mathrm{Pd}_{2}($ Ref. 21$)$ & $\mathrm{Pd}_{2}^{-}$(Ref. 21) \\
\hline Electronic state & $\mathrm{X}$ & $\mathrm{X}$ & $\mathrm{X} 4 d^{19} 5 s \sigma_{g}^{1}$ & $\mathrm{X} 4 d^{19} 5 s \sigma_{g}^{2}$ \\
$\hbar \omega_{e} / \mathrm{meV}$ & $20.3 \pm 1.0^{\mathrm{a}}$ & $18.0 \pm 2.0$ & $26.0 \pm 1.2$ & $25.5 \pm 1.9$ \\
$k / \mathrm{N} \mathrm{m}^{-1}$ & $106 \pm 10$ & $83 \pm 20$ & 137 & 132 \\
$\Delta r_{e} / \AA$ & $0.081 \pm 0.002$ & & 0.037 & \\
& $\left(r_{e}\right.$ of anion smaller $)$ & $\left(r_{e}\right.$ of anion smaller $)$ \\
Electron affinity/eV & $0.876 \pm 0.05$ & $1.685 \pm 0.008$ & \\
\hline \hline
\end{tabular}

${ }^{\mathrm{a}} \omega_{e} x_{e}=(0.5 \pm 0.1) \mathrm{meV}$.

shows the Franck-Condon fit corresponding to the stretch vibration along the $\mathrm{Pd}-\mathrm{Pd}$ normal coordinate of $\mathrm{Pd}_{2}\left(\mathrm{C}_{6} \mathrm{H}_{6}\right)$. A vibrational energy of $20.3 \mathrm{meV}$ and $18.0 \mathrm{meV}$ is revealed for $\mathrm{Pd}_{2}\left(\mathrm{C}_{6} \mathrm{H}_{6}\right)$ and $\mathrm{Pd}_{2}\left(\mathrm{C}_{6} \mathrm{H}_{6}\right)^{-}$, respectively. These small vibrational energies are characteristic for a $\mathrm{Pd}-\mathrm{Pd}$ stretch vibration; e.g., the ground state vibrational energy of $\mathrm{Pd}_{2}$ is $26 \mathrm{meV} \cdot{ }^{25,26}$ The only slightly modified vibrational energy serves as evidence that the palladium dimer is free to vibrate along its intermetallic bond. This suggests that the benzene is bound to $\mathrm{Pd}_{2}$ in a similar configuration to that of $\mathrm{Pt}_{2}\left(\mathrm{C}_{6} \mathrm{H}_{6}\right)$.

According to the reduced masses $\left(\mu_{\mathrm{Pd}-\mathrm{PdBz}}\right.$ $=67.495 \mathrm{amu}, \mu_{\mathrm{Pd}-\mathrm{Pd}}=53.21 \mathrm{amu}$ ), an intermetallic vibrational energy of $23 \mathrm{meV}$ is expected for $\mathrm{Pd}_{2}\left(\mathrm{C}_{6} \mathrm{H}_{6}\right)$ assuming the same force constant as that of $\mathrm{Pd}_{2}$. However, the observed vibrational energy of $\mathrm{Pd}_{2}\left(\mathrm{C}_{6} \mathrm{H}_{6}\right)$ is $12 \%$ smaller which suggests a reduced intermetallic force constant with respect to $\mathrm{Pd}_{2}$. The anionic vibrational energy is $20 \%$ smaller than expected by the mass difference of reacted and unreacted $\mathrm{Pd}_{2}$. The weakening of the intermetallic bond in both anionic and neutral $\mathrm{Pd}_{2}\left(\mathrm{C}_{6} \mathrm{H}_{6}\right)$ indicates a charge transfer from the ligand into an antibonding $\mathrm{Pd}_{2}$-orbital. Note, however, that the intermetallic bond length difference $\Delta r_{e}$ between $\mathrm{Pd}_{2}\left(\mathrm{C}_{6} \mathrm{H}_{6}\right)^{-}$and $\mathrm{Pd}_{2}\left(\mathrm{C}_{6} \mathrm{H}_{6}\right)$ is distinctly larger (8.1 pm) than that between $\mathrm{Pd}_{2}^{-}$and $\mathrm{Pd}_{2}(3.7 \mathrm{pm})$. The positive change of the bond length upon electron detachment from

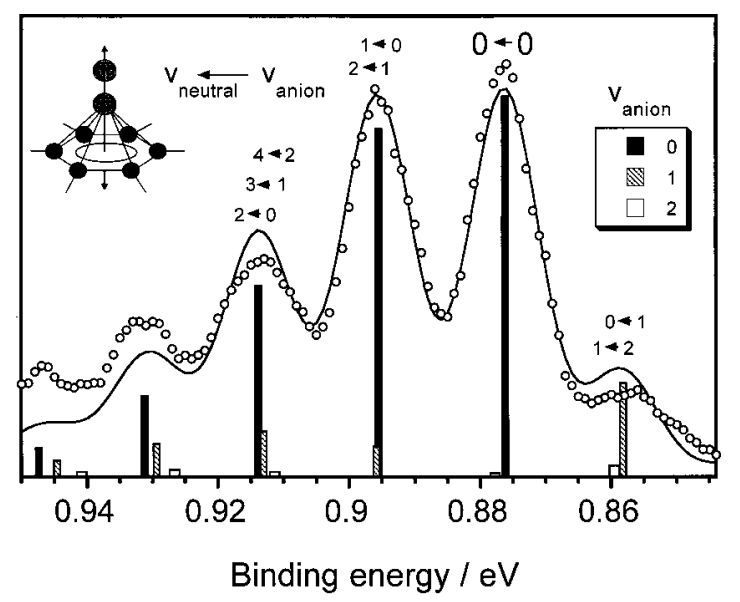

FIG. 6. Anharmonic Franck-Condon analysis of the vibrational fine structure of the ground state photoelectron peak of $\mathrm{Pd}_{2}\left(\mathrm{C}_{6} \mathrm{H}_{6}\right)^{-}$along the $\mathrm{Pd}-\mathrm{Pd}\left(\mathrm{C}_{6} \mathrm{H}_{6}\right)^{-}$stretch coordinate. The adiabatic electron affinity of $\mathrm{Pd}_{2}\left(\mathrm{C}_{6} \mathrm{H}_{6}\right)$ amounts to $0.876 \mathrm{eV}$. The bars represent the Franck-Condon factors.
$\mathrm{Pd}_{2}\left(\mathrm{C}_{6} \mathrm{H}_{6}\right)^{-}$anticipates that the extra electron is detached from a bonding orbital, in analogy to detachment from $\mathrm{Pd}_{2}^{-}$ for which a leading configuration $\mathrm{X} 4 d^{19} 5 s \sigma_{g}^{2}$ is proposed. ${ }^{21}$ In contrast to the direction of the bond length change, the comparison of the bond strength suggests detachment from an antibonding orbital as the bond strength in neutral $\operatorname{Pd}_{2}\left(\mathrm{C}_{6} \mathrm{H}_{6}\right)$ is somewhat stiffer $\left(106 \mathrm{~N} \mathrm{~m}^{-1}\right)$ than in the anion $\left(83 \mathrm{~N} \mathrm{~m}^{-1}\right.$ ). This seeming contradiction points to the fact that the single-particle picture is not sufficient for an interpretation. The total electron rearrangement upon detachment of the uppermost " $5 s \sigma_{g}$ "'-derived bonding orbital leads not just to a change of the bond length but also to an increase of the potential curvature. From this an overall strengthening of the intermetallic bond strength results, though the bond length increases upon detachment. The enhanced reorganization of the electrons upon detachment from $\mathrm{Pd}_{2}\left(\mathrm{C}_{6} \mathrm{H}_{6}\right)^{-}$is also consistent with the drastically reduced electron affinity of $\mathrm{Pd}_{2}\left(\mathrm{C}_{6} \mathrm{H}_{6}\right)$ with respect to $\mathrm{Pd}_{2}$. The electron affinities of $\mathrm{Pt}_{2}$ and $\mathrm{Pt}_{2}\left(\mathrm{C}_{6} \mathrm{H}_{6}\right)$, on the other hand, differ only marginally as the electron configurations are proposed to be closely related.

Similar to the spectrum of $\mathrm{Pt}_{2}\left(\mathrm{C}_{6} \mathrm{H}_{6}\right)^{-}$, the strong interaction of the $d$-orbitals with the orbitals of benzene leads to a considerable change in the photodetachment intensity and peak structure of $\mathrm{Pd}_{2}\left(\mathrm{C}_{6} \mathrm{H}_{6}\right)^{-}$with respect to $\mathrm{Pd}_{2}^{-}$. The hybridization of the $d$-orbitals of palladium with the frontier orbitals of benzene is evident from the enhanced photoelectron intensity above $2 \mathrm{eV}$ where the transitions within the $d$-orbital region are predicted for palladium. ${ }^{21,25}$ The photodetachment spectrum of $\mathrm{Pd}_{2}^{-}$(Ref. 25) shows only a weak photoemission intensity in this binding energy region, which is explained by the small photoemission cross sections of the $d$-orbitals. However, chemisorption of benzene activates the $d$-orbitals significantly. The interaction of the $d$-derived orbitals with both the HOMO and LUMO of benzene generates hybridized metal-adsorbate orbitals of $d \pi_{u, g}-p \pi$ and $d \delta_{u, g}-p \pi^{*}$ symmetry, respectively. Such a hybridization leads to an enhanced cross section in the $d$-orbital region due to the partial $p \pi$-character of the hybridized wave functions as well as to an energy splitting by bonding and antibonding combinations.

Upon reaction with benzene the intermetallic bond strength decreases in both $\mathrm{Pd}_{2}\left(\mathrm{C}_{6} \mathrm{H}_{6}\right)$ and $\mathrm{Pt}_{2}\left(\mathrm{C}_{6} \mathrm{H}_{6}\right)$, as well as in the corresponding anions. The stronger vibrational progression observed on the ground state peak of $\mathrm{Pt}_{2}\left(\mathrm{C}_{6} \mathrm{H}_{6}\right)^{-}$ 


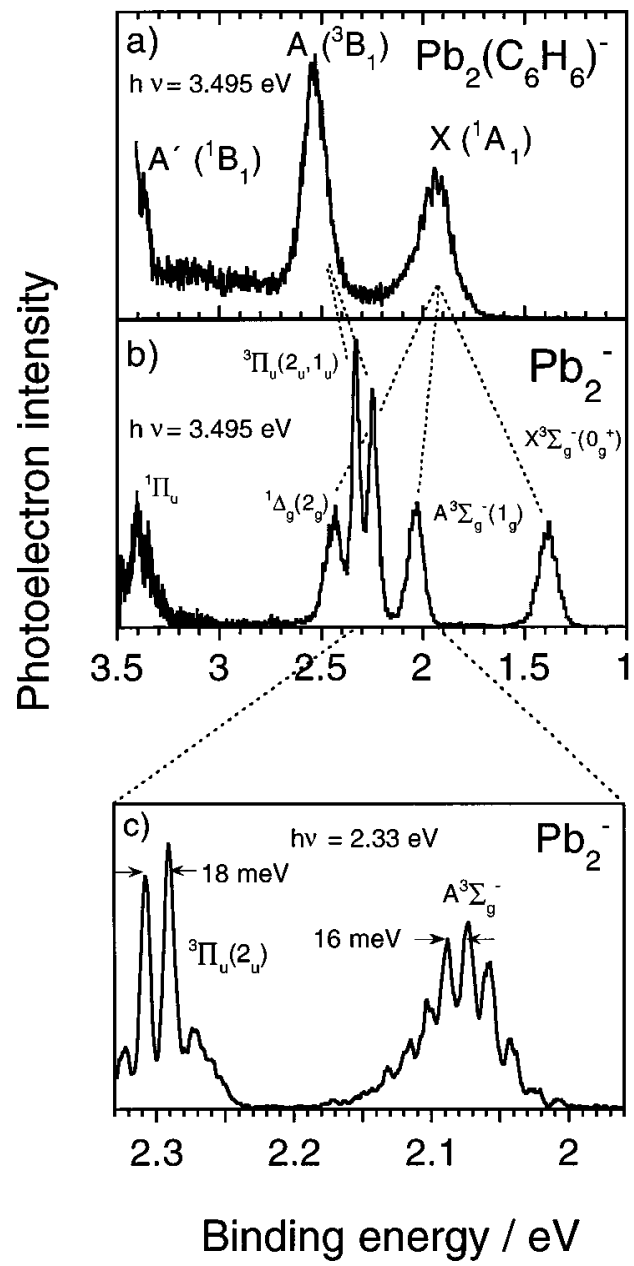

FIG. 7. The photoelectron detachment spectrum of $\mathrm{Pb}_{2}\left(\mathrm{C}_{6} \mathrm{H}_{6}\right)^{-}$recorded at a photon energy of $3.495 \mathrm{eV}$ is shown in (a). The vertical electron affinity of $\mathrm{Pb}_{2}\left(\mathrm{C}_{6} \mathrm{H}_{6}\right)$ amounts to $(1.95 \pm 0.05) \mathrm{eV}$. The photodetachment spectra of free $\mathrm{Pb}_{2}^{-}$at a photon energy of $3.495 \mathrm{eV}$ and $2.330 \mathrm{eV}$ are shown in (b) and (c), respectively. ${ }^{3} \Sigma_{g}$ denotes the ground state of neutral $\mathrm{Pb}_{2}$ which is split by a spin-orbit coupling of $0.65 \mathrm{eV}$ (Refs. 35,36 ).

makes likely a more steeper rise of the potential for the chemisorbed platinum cluster, which-in turn-corresponds to the stronger intermetallic force constant of $\mathrm{Pt}_{2}\left(\mathrm{C}_{6} \mathrm{H}_{6}\right)(255$ $\left.\mathrm{N} \mathrm{m}^{-1}\right)$ compared to $\mathrm{Pd}_{2}\left(\mathrm{C}_{6} \mathrm{H}_{6}\right)\left(106 \mathrm{~N} \mathrm{~m}^{-1}\right)$. In particular, the force constants of $\mathrm{Pd}_{2}\left(\mathrm{C}_{6} \mathrm{H}_{6}\right)$ and $\mathrm{Pd}_{2}\left(\mathrm{C}_{6} \mathrm{H}_{6}\right)^{-}$are $3 / 4$ and $2 / 3$ that of $\mathrm{Pd}_{2}$ and $\mathrm{Pd}_{2}^{-}$, respectively. The weakening of the intermetallic bond in $\mathrm{Pd}_{2}\left(\mathrm{C}_{6} \mathrm{H}_{6}\right)$ relative to $\mathrm{Pd}_{2}$ is larger than in $\mathrm{Pt}_{2}\left(\mathrm{C}_{6} \mathrm{H}_{6}\right)$ which is less than $5 \%$ smaller than that of unreacted $\mathrm{Pt}_{2}$.

\section{C. $\mathrm{Pb}_{2}\left(\mathrm{C}_{6} \mathrm{H}_{6}\right)^{-}$}

Photodetachment spectra of $\mathrm{Pb}_{2}\left(\mathrm{C}_{6} \mathrm{H}_{6}\right)^{-}$and $\mathrm{Pb}_{2}^{-}$are shown in Fig. 7. The spectra have been recorded at photon energies of $3.495 \mathrm{eV}$ [Figs. 7(a) and 7(b)] and $2.33 \mathrm{eV}$ [Fig. $7(\mathrm{c})]$, respectively. The $\mathrm{Pb}_{2}^{-}$-spectrum has been assigned by Ho et al. ${ }^{35}$ The first five peaks are due to detachment of the $6 p$-derived orbitals as the bonding in $\mathrm{Pb}_{2}$ is mainly governed by the degenerate $6 p \pi_{u}$ orbital. $^{36,37}$ Both the triplet ground state of $\mathrm{Pb}_{2}, 2 \sigma_{g}^{2} 1 \pi_{u}^{2}\left({ }^{3} \Sigma_{g}^{-}\right)$, and the first excited triplet state, $2 \sigma_{g}^{1} 1 \pi_{u}^{3}\left({ }^{3} \Pi_{u}\right)$, are coupled by spin-orbit interaction which results in a splitting of the ground state electron peak $\left(0_{g}^{+}, 1_{g}\right)$ and the excited ${ }^{3} \Pi_{u}$ final peak $\left(2_{u}, 1_{u}\right){ }^{35,36}$ The corresponding singlet state of the ${ }^{1} \Pi_{u}$ state is located at $\sim 3.4$ $\mathrm{eV}$. The ${ }^{1} \Delta_{u}$ peak at $2.45 \mathrm{eV}$ results from the ground state configuration $2 \sigma_{g}^{2} 1 \pi_{u}^{2}$. In contrast to the spectrum of $\mathrm{Pb}_{2}^{-}$, only two dominant peaks $(X, A)$ are seen in the spectrum of $\mathrm{Pb}_{2}\left(\mathrm{C}_{6} \mathrm{H}_{6}\right)^{-}$[Fig. 7(a)]. A third peak $\left(A^{\prime}\right)$ is indicated at 3.4 $\mathrm{eV}$. This reduced number of peaks suggests a closed shell electron configuration in $\mathrm{Pb}_{2}\left(\mathrm{C}_{6} \mathrm{H}_{6}\right)$ which considerably reduces the number of final state peaks due to a missing spinorbit splitting. A closed shell electronic structure with nondegenerated orbitals is expected, i.e., in $C_{2 v}$-symmetry. Thus a possible geometry is a $\mathrm{Pb}_{2}$-molecule lying horizontally above the benzene plane. Such a geometry has been calculated for $\mathrm{Rh}_{2}\left(\mathrm{C}_{6} \mathrm{H}_{6}\right)^{+}$(Ref. 15) to be the most stable one. In $C_{2 v}$-symmetry the degenerate $6 p \pi$ orbitals transform into an $a_{1}$ and a $b_{1}$ orbital. The $a_{1}$ orbital is filled by the two $6 p \pi$ electrons resulting in a totally symmetric singlet final state $\left(a_{1}^{2}\right)$. This closed shell ground state configuration results in a single ground state peak in contrast to $\mathrm{Pb}_{2}$ for which the open shell ground state configuration gives rise to several final state peaks as discussed above. As indicated in Fig. 7 three of the peaks below $2.5 \mathrm{eV}$ combine to form a single peak in the spectrum of $\mathrm{Pb}_{2}\left(\mathrm{C}_{6} \mathrm{H}_{6}\right)^{-}$. The $b_{1}$ orbital has one nodal plane which is therefore expected to give rise to the first excited triplet state $\left(a_{1}^{1} b_{1}^{1}\right)\left({ }^{3} B_{1}\right)$ labeled $\mathrm{A}$ in Fig. 7(a). The corresponding singlet final state peak $\left({ }^{1} B_{1}\right)$ could be assigned to the small feature at $3.4 \mathrm{eV}\left(A^{\prime}\right)$. This interpretation is supported by the fact that the singlet-triplet splitting of the first excited state of $\mathrm{Pb}_{2}\left(\mathrm{C}_{6} \mathrm{H}_{6}\right)$ is very similar to the singlet-triplet splitting of the first excited electron configuration of $\mathrm{Pb}_{2} \quad\left(2 \sigma_{g}^{1} 1 \pi_{u}^{3}\right)$ which amounts to $\sim 1 \mathrm{eV}$ $\left({ }^{3} \Pi_{u},{ }^{1} \Pi_{u}\right)$.

In contrast to $\mathrm{Pb}_{2}^{-}$no vibrational fine structure could be resolved on the valence photoelectron peaks of $\mathrm{Pb}_{2}\left(\mathrm{C}_{6} \mathrm{H}_{6}\right)^{-}$ neither with 3.49 nor with $2.33 \mathrm{eV}$ photons. This is another hint for the reduced symmetry of $\mathrm{Pb}_{2}\left(\mathrm{C}_{6} \mathrm{H}_{6}\right)$ with respect to the unreacted dimer. In $C_{2 v}$-symmetry, eleven totally symmetric vibrational modes $\left(\Gamma_{\mathrm{vib}}=11 A_{1}+8 A_{2}+7 B_{1}+10 B_{2}\right)$ are possible which might be difficult to resolve even if only some of them are excited. The vibrational broadening also explains the missing spin-orbit splitting of the ${ }^{3} B_{1}$ final state peak $^{35}$ at $2.5 \mathrm{eV}$ in Fig. 7(a) (A). Note that this peak is much broader than the experimental resolution. It is most likely broadened by internal vibrational excitations in contrast to the analogous peak of $\mathrm{Pb}_{2}$ at $2.3 \mathrm{eV}$ binding energy [Fig. 7(b)]. A single vibrational mode of $18 \mathrm{meV}$ [Fig. 7(c)] can be resolved on the $2{ }_{u}$-spin-orbit component of $\mathrm{Pb}_{2}^{-}$(Ref. 35) using a photon energy of $2.33 \mathrm{eV}$. This resolution cannot be achieved at a photon energy of $3.495 \mathrm{eV}$, neither for $\mathrm{Pb}_{2}\left(\mathrm{C}_{6} \mathrm{H}_{6}\right)^{-}$nor $\mathrm{Pb}_{2}^{-}$. Still the spin-orbit components of $\mathrm{Pb}_{2}^{-}$are much smaller than the A-peak of $\mathrm{Pb}_{2}\left(\mathrm{C}_{6} \mathrm{H}_{6}\right)^{-}$. We attribute this broadening to a simultaneous excitation of both $\mathrm{Pb}$ - and benzene-derived modes in $\mathrm{Pb}_{2}\left(\mathrm{C}_{6} \mathrm{H}_{6}\right)$ indicating a strong interaction of the $\mathrm{Pb}$-derived $6 p \pi$-orbital with the HOMO $\left(e_{1 g}\right)$ of benzene. This is different to $\mathrm{Pt}_{2}\left(\mathrm{C}_{6} \mathrm{H}_{6}\right)$ and $\mathrm{Pd}_{2}\left(\mathrm{C}_{6} \mathrm{H}_{6}\right)$ in which the ground state transition peak $(6 s \sigma$ and $5 s \sigma)$ reveals only the intermetallic stretching vibration. This is consistent with the fact that the benzene modes couple much easier to the intermetallic stretch vibration of 
the horizontally bound $\mathrm{Pb}_{2}$ than to the perpendicular oriented transition metal dimers $\mathrm{Pt}_{2}$ and $\mathrm{Pd}_{2}$.

\section{SUMMARY}

Laser photodetachment electron spectra of $\mathrm{Pt}_{2}\left(\mathrm{C}_{6} \mathrm{H}_{6}\right)^{-}$, $\mathrm{Pd}_{2}\left(\mathrm{C}_{6} \mathrm{H}_{6}\right)^{-}$, and $\mathrm{Pb}_{2}\left(\mathrm{C}_{6} \mathrm{H}_{6}\right)^{-}$have been measured in the gas phase using photon energies of 1.165, 2.330, and $3.495 \mathrm{eV}$. Vibrational energies of $(24.2 \pm 1)$ and $(20.3 \pm 1) \mathrm{meV}$ have been resolved on the ground state photoelectron peaks of $\mathrm{Pt}_{2}\left(\mathrm{C}_{6} \mathrm{H}_{6}\right)$ and $\mathrm{Pd}_{2}\left(\mathrm{C}_{6} \mathrm{H}_{6}\right)$, respectively. The vibrational en-

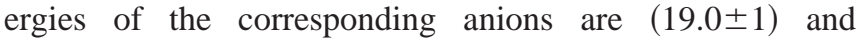
$(18.0 \pm 2) \mathrm{meV}$ for $\mathrm{Pt}_{2}\left(\mathrm{C}_{6} \mathrm{H}_{6}\right)^{-}$and $\mathrm{Pd}_{2}\left(\mathrm{C}_{6} \mathrm{H}_{6}\right)^{-}$. From the adiabatic vibronic transition and a Franck-Condon analysis the precise electron affinities have been determined for $\mathrm{Pt}_{2}\left(\mathrm{C}_{6} \mathrm{H}_{6}\right)(2.006 \pm 0.05 \mathrm{eV})$ and $\mathrm{Pd}_{2}\left(\mathrm{C}_{6} \mathrm{H}_{6}\right) \quad(0.876 \pm 0.05$ $\mathrm{eV})$. Moreover, the Franck-Condon analysis of the ground state transitions reveals that the intermetallic $\sigma$-bond of $\mathrm{Pd}_{2}\left(\mathrm{C}_{6} \mathrm{H}_{6}\right)$ is much weaker than that of unreacted $\mathrm{Pd}_{2}$. The intermetallic bond strength of $\mathrm{Pt}_{2}$, in contrast, is hardly any weakened upon chemisorption of benzene. A significant enhancement of the photoelectron intensity in the binding energy region of the $d$-orbitals indicates a strong $d(\pi, \delta)-p \pi$ hybridization between the orbitals of the transition metal dimers and benzene. The vibrational analysis of the $\mathrm{Pt}_{2}\left(\mathrm{C}_{6} \mathrm{H}_{6}\right)^{-}$and $\mathrm{Pd}_{2}\left(\mathrm{C}_{6} \mathrm{H}_{6}\right)^{-}$photodetachment spectra suggests a perpendicular orientation of the benzene plane relative to the metal dimer axis resulting in a $C_{6 v}$-symmetry in contrast to the local $C_{2 v}$ and $C_{3 v}$ symmetries on densely packed surfaces. Due to the missing spin-orbit splitting of the ground state photoelectron peak of $\mathrm{Pb}_{2}\left(\mathrm{C}_{6} \mathrm{H}_{6}\right)$, the metal-arene cluster is suggested to have a closed shell electronic configuration in contrast to unreacted $\mathrm{Pb}_{2}$. In contrast to $\mathrm{Pt}_{2}\left(\mathrm{C}_{6} \mathrm{H}_{6}\right)$ and $\mathrm{Pd}_{2}\left(\mathrm{C}_{6} \mathrm{H}_{6}\right)$ the benzene molecule is predicted to be bound parallel to $\mathrm{Pb}_{2}$ in $C_{2 v}$-symmetry.

\section{ACKNOWLEDGMENTS}

This work was supported by the Sonderforschungsbereich SFB 341 of the Deutsche Forschungsgemeinschaft. We are also grateful to H. Pfeifer, J. Lauer, B. Küpper, and K. Wingerath for technical and computational support. Furthermore, we would like to thank the anonymous referee for his valuable comments.
${ }^{1}$ E. L. Muetterties, Science 196, 839 (1977)

${ }^{2}$ A. M. Bradshaw, Surf. Sci. 331-333, 978 (1995).

${ }^{3}$ E. L. Muetterties, J. R. Bleeke, E. J. Wucherer, and T. A. Albright, Chem. Rev. 82, 499 (1982)

${ }^{4}$ C. W. Bauschlicher, Jr., H. Partridge, and S. R. Langhoff, J. Phys. Chem. 96, 3273 (1992).

${ }^{5}$ A. Ouhlal, A. Selmani, and A. Yelon, Chem. Phys. Lett. 243, 269 (1995).

${ }^{6}$ S. M. Mattar and R. Sammynaiken, J. Chem. Phys. 106, 1080 (1997).

${ }^{7}$ G. Ganteför, K. H. Meiwes-Broer, and H. O. Lutz, Phys. Rev. A 37, 2716 (1988)

${ }^{8}$ O. Cheshnovsky, K. J. Taylor, J. Conceicao, and R. E. Smalley, Phys. Rev. Lett. 64, 1785 (1990).

${ }^{9}$ G. Schulze Icking-Konert, H. Handschuh, G. Ganteför, and W. Eberhardt, Phys. Rev. Lett. 74, 1095 (1995).

${ }^{10}$ X. B. Wang and L. S. Wang, Nature (London) 400, 245 (1999).

${ }^{11}$ D. J. Trevor, R. L. Whetten, D. M. Cox, and A. Kaldor, J. Am. Chem. Soc. 107, 518 (1985)

${ }^{12}$ K. F. Willey, C. S. Yeh, D. L. Robbins, and M. A. Duncan, J. Phys. Chem. 96, 9106 (1992).

${ }^{13}$ C. Berg, M. Beyer, T. Schindler, G. Niedner-Schatteburg, and V. E. Bondybey, J. Chem. Phys. 104, 7940 (1996).

${ }^{14}$ S. Afzaal and B. S. Freiser, Chem. Phys. Lett. 218, 254 (1994).

${ }^{15}$ D. Majumdar, S. Roszak, and K. Balasubramanian, J. Chem. Phys. 107, 408 (1997).

${ }^{16}$ S. Roszak and K. Balasubramanian, Chem. Phys. Lett. 234, 101 (1995).

${ }^{17}$ K. Hoshina, T. Kurikawa, H. Takeda, A. Nakajima, and K. Kaya, J. Phys. Chem. 99, 3053 (1995).

${ }^{18}$ T. Yasuike and S. Yabushita, J. Phys. Chem. A 103, 4533 (1999).

${ }^{19}$ K. Judai, M. Hirano, H. Kawamata, S. Yabushita, A. Katajima, and K. Kaya, Chem. Phys. Lett. 270, 23 (1997).

${ }^{20}$ H. Handschuh, G. Ganteför, and W. Eberhardt, Rev. Sci. Instrum. 66, 3838 (1995)

${ }^{21}$ J. Ho, K. M. Ervin, M. L. Polak, M. K. Gilles, and W. C. Lineberger, J. Chem. Phys. 99, 8542 (1993).

${ }^{22}$ K. Balasubramanian, J. Chem. Phys. 87, 6573 (1987).

${ }^{23}$ S. Roszak and K. Balasubramanian, J. Chem. Phys. 103, 1043 (1995).

${ }^{24}$ A. B. Anderson, M. R. McDevitt, and F. L. Urbach, Surf. Sci. 146, 80 (1984).

${ }^{25}$ J. Ho, K. M. Ervin, M. L. Polak, M. K. Gilles, and W. C. Lineberger, J. Chem. Phys. 95, 4845 (1991).

${ }^{26}$ K. Balasubramanian, J. Chem. Phys. 89, 6310 (1988).

${ }^{27}$ F. P. Netzer and J. U. Mack, J. Chem. Phys. 79, 1017 (1983).

${ }^{28}$ J. Sommers, M. E. Bridge, D. R. Lloyd, and T. McCabe, Surf. Sci. 181, L167 (1987).

${ }^{29}$ P. S. Weiss and D. M. Eigler, Phys. Rev. Lett. 19, 3139 (1993).

${ }^{30}$ M. Doering, H.-P. Rust, B. G. Briner, and A. M. Bradshaw, Surf. Sci. 410, L736 (1998).

${ }^{31}$ P. Sautet and M.-L. Bocquet, Phys. Rev. B 53, 4910 (1996).

${ }^{32}$ M. Ohno and W. von Niessen, Phys. Rev. B 55, 4787 (1997).

${ }^{33}$ R. Hoffmann, Rev. Mod. Phys. 60, 601 (1988).

${ }^{34}$ D. Dai, S. Roszak, and K. Balasubramanian, J. Chem. Phys. 104, 1471 (1996).

${ }^{35}$ J. Ho, M. L. Polak, and W. C. Lineberger, J. Chem. Phys. 96, 144 (1992).

${ }^{36}$ K. Balasubramanian and K. S. Pitzer, J. Chem. Phys. 78, 321 (1983).

${ }^{37}$ J. Onoe, J. Phys. Soc. Jpn. 66, 2328 (1997). 